\title{
Pengaruh Pembelajaran Pendidikan Jasmani, OlahragaDan Kesehatan Terhadap Pembinaan Karakter Siswa
}

\author{
Firman $^{1}$, Suwirman ${ }^{2}$, Roni Yenes ${ }^{2}$ \\ ${ }^{123}$ Fakultas Ilmu Keolahragaan, Universitas Negeri Padang, Indonesia. \\ E-mail: firman@yahoo.com ${ }^{1}$, suwirman@,fik.unp.ac.id ${ }^{2}$, ryenes@yahoo.co.id ${ }^{3}$
}

\begin{abstract}
Abstrak
Penelitian ini asli dari hasil pengamatan penelitian tentang masalah yang terjadi pada siswa SMP di Kecamatan Rao, nampak bahwa karakter siswa cenderung rendah. Masalah itu diduga disebabkan oleh beberapa faktor, salah satunya adalah proses pembelajaran pendidikan jasmani. Oleh karena itu, penulis tertarik untuk memperoleh informasi dan mengetahui pengaruh pembelajaran pendidikan jasmani, olahraga, dan kesehatan pada pembentukan karakter siswa di Sekolah Menengah Distrik Rao.

Jenis penelitian ini adalah Expost facto dan data diambil langsung melalui teknik kuesioner. Populasinya adalah semua siswa SMP Negeri Se Rao yang berjumlah 752 orang, sampel penelitian adalah 75 orang yang mengambilnya menggunakan teknik Propotional Stratufed random sampling. Alat yang digunakan untuk pengumpulan data adalah tes kuesioner, kemudian dianalisis dengan teknik uji t plastik.

Sebelum uji t dilakukan, uji persyaratan analisis adalah uji normalitas. Untuk data penelitian siswa Se Se Rao Lo 0,0938 dengan Lt pada $\alpha=0,05$ 0,1023 dengan demikian Lo <dari Lt dapat disimpulkan bahwa data yang diperoleh berdistribusi normal.

Hasil analisis uji hipotesis diperoleh th $-6,1894>$ ttabel 1,6853 pada taraf signifikansi $\alpha=0,05$ pada jumlah sampel sebesar 75. Jadi, dapat disimpulkan bahwa Ho ditolak dan Ha diterima. Dengan demikian Pembelajaran Pendidikan Jasmani, Olahraga dan kesehatan memiliki pengaruh yang signifikan terhadap pengembangan karakter siswa SMP Negeri Rao.

Berdasarkan analisis dan diskusi data, dapat disimpulkan bahwa: Pembelajaran Pendidikan Jasmani, Olahraga dan kesehatan memiliki pengaruh yang signifikan terhadap pengembangan karakter siswa SMP di Kabupaten Rao

Kata Kunci: Pembelajaran, Pendidikan Jasmani, Kesehatan, Karakter
\end{abstract}

\begin{abstract}
This study original from the results of observations of research on the problems that occur in junior high school students in Rao Subdistrict, it appears that the character of students tends to be low. That problem is allegedly caused by several factors, one of which is the physical education learning process. Therefore, the writer was interested in obtaining information and knowing the effect of learning physical education, sports and health on the character building of students in the Rao District Middle School.

This type of research is Expost facto and data is taken directly through questionnaire techniques. the population is all students of SMP Se Rao Subdistrict, amounting to 752 people, the sample of research is 75 people who took it using Propotional Stratufed random sampling technique. The tool used for data collection was a questionnaire test, then analyzed with a plastic t test technique.
\end{abstract}


Before the t test is carried out, the test of the analysis requirements is the normality test. For research data of students of Se District Rao Lo 0.0938 with Lt at $\alpha=0.050 .1023$ thus Lo $<$ from Lt it can be concluded that the data obtained are normally distributed.

The results of the hypothesis test analysis obtained thit -6,1894> t table 1.6853 at the significance level $\alpha=0.05$ in the number of samples amounting to 75. So, it can be concluded that Ho is rejected and $\mathrm{Ha}$ is accepted. Thus Physical Education Learning, Sports and health have a significant influence on the character development of Rao District Junior High School students.

Based on data analysis and discussion, it can be concluded that: Physical Education Learning, Sports and health have a significant influence on the character development of students Junior High School in Rao District

Keywords: Learning, Physical Education, Health, Character

\section{PENDAHULUAN}

Pendidikan jasmani, olahraga dan kesehatan idealnya memiliki peran strategis dalam membantu terwujudnya generasi muda yang berkarakter. Hal ini juga diperkuat fungsi dan tujuan penjasorkes tidak hanya berorientasi pada keterampilan fisik semata, tetapi juga berorientasi kepada penanaman nilai-nilai karakter yang terdapat didalam materi pembelajaran penjasorkes.

Pendidikan juga bertujuan mewujudkan cita-cita manusia yaitu berkehidupan sesuai dengan fitrahnya. Kehidupan yang sesuai dengan fitrah manusia adalah panduan utuh antara aspek duniawi dan ukhrowi, kehidupan individu dan sosial, serta beriman, berilmu dan beramal untuk mencapai kebahagiaan hidup dunia dan akhirat. Tujuan ini selaras dengan fungsi dan tujuan pendidikan nasional. Undang-Undang Sistem Pendidikan Nasional No. 20 tahun 2003 menyebutkan;

"Pendidikan nasional berfungsi mengembangkan kemampuan dan membentuk serta peradaban bangsa yang bermartabat dalam rangka mencerdaskan kehidupan bangsa bertujuan untuk berkembangnya potensi peserta didik agar menjadi manusia yang beriman dan bertaqwa kepada Tuhan Yang Maha Esa, berakhlak mulia, sehat, berilmu, cakap, kreatif, mandiri, dan menjadi manusia yang bertanggung jawab."

Namun pada kenyataaan yang penulis temukan di lapangan pada saat oberservasi pada tanggal 7 sampai dengan tanggal 11 Agustus 2017 adanya ketidak sesuaian antara Pelajaran Pendidkan Jasmani, olahraga dan kesehatan dengan Pembinaan karakter siswa. Hal ini terlihat dari beberapa fenomena yang penulis temukan sebagai berikut: 1) Masih ada beberapa siswa yang terlambat hadir ketika jam pelajaran berlangsung.

Hal ini terlihat ketika jam pelajaran sudah dimulai akan tetapi masih ada bebrapa siswa yang berada di luar kelas atau di kantin sekolah, padahal guru telah masuk kedalam kelas, 2) Banyaknya siswa yang tidak memiliki kesadaran dalam melaksanakan ibadah wajib. Hal ini terlihat ketika jadwal sholat berjamaah perkelas. Hanya beberapa siswa yang melaksanakan ibadah sholat berjamaah dimushola sekolah, 3)Kurangnya rasa tanggungjawab beberapa siswa dalam pembelajaran disekolah.

Terlihat dari beberapa siswa yang tidak mau membantu temannya mengembalikan peralatan atau media yang digunakan setelah pelajaran berakhir. 4) Masih ada beberapa siswa yang mengerjakan pekerjaan rumah di sekolah. hal ini terlihat dari adanya siswa yang mengerjakan tugas (pekerjaan rumah) dengan cara mencontoh tugas kepada temannya di sekolah. Berdasarkan permasalahan di atas, penulis tertarik melakukan Penelitian untuk mengetahui pengaruh pembelajaran Penjasorkes terhadap Pembinaan karakter Siswa SMP Se-Kecamatan Rao.

Tujuan penelitian ini Untuk mengetahui pengaruh pembelajaran pendidikan jasmani, olahraga dan kesehatan terhadap Pembinaan karakter siswa SMP Se-Kecamatan Rao. Penelitian Adapun Indikator Nilai-Nilai Karakter dalam Pendidikan Jasmani, Olahraga dan Kesehatan Sebagai Berikut. 
METODE

Penelitian ini adalah penelitian Ex-post Facto. Variabel dalam penelitian ini ada dua, pertama, variabel sebab (bebas) yaitu pembelajaran Pendidikan jasmani dan kesehatan yang dilakukan oleh guru, dan kedua, variabel akibat (terikat) yaitu Karakter siswa. Populasi dalam penelitian ini adalah seluruh siswa SMP Se-Kecamatan Rao yang terdaftar pada tahun pelajaran 2018/2019 yang berjumlah 752 orang.

Dalam penelitian ini, sampel diambil secara cluster sampling yaitu bilamana populasi tidak terdiri dari individu-individu melainkan terdiri dari kelompok-kelompok individu atau cluster. Maka sampel yang diambil dalam penelitian ini adalah $10 \mathrm{~s} / \mathrm{d} 20 \%$ dari keseluruhan siswa setiap sekolah SMP Se-Kecamatan Rao yang terdaftar pada tahun ajaran 2018/2019. Maka didapat total Sampel dalam penelitian ini adalah 75 orang siswa. Alat pengumpulan data yang digunakan adalah angket.

\section{HASIL DAN PEMBAHASAN \\ Hasil Penelitian}

Hasil penelitian akan digambarkan sesuai dengan tujuan hipotesis yang diajukan sebelumnya.Pengumpulan data pada penelitian ini menggunakan instrument berupa kuisoner atau angket. Pemberian angket ditujukan kepada reponden penelitian yaitu orang tua dari siswa SMP Se Kecamatan Rao. Responden penelitian ini berjumlah 75 Siswa. Pengumpulan data melalui angket dilakukan langsung oleh peneliti kepada orang tua siswa dengan cara menemui langsung ke rumah responden.

Berdasarkan penjelasan serta uraian yang telah dikumpulkan sebelumnya, maka dalan bab ini akan dilakukan analisis dan pembahasan yang diperoleh dalam penelitian ini. Hasil penelitian akan digambarkan sesuai dengan tujuan hipotesis yang diajukan sebelumnya

Setelah data dinilai dan dijumlahkan, kemudian dibandingkan kriteria perbandimgam untuk mencari klasifikasi: sangat baik, baik, sedang, kurang, dan kurang sekali. Untuk mencapai persentase dilakukan penjumlahan klasifikasi kemudian dibandingkan dengan jumlah sampel dan dikali $100 \%$ maka hasilnya dibandingkan. Gambaran masing-masing data dapat dilihat pada deskripsi berikut ini:

\section{Analisis Data}

Berikut ini akan dianalisis permasalahan yang dipaparkan dalam penelitian ini secara berurutan mengenai Pengaruh Pembelajaran Pendidikan Jasmani, Olahraga dan kesehatan terhadap Pembinaan Karakter Siswa SMP N Se Kecamatan Rao, antara lain:

a. Pengaruh Pembelajaran Pendidikan Jasmani, Olahraga dan kesehatan terhadap Pembinaan Karakter Siswa SMP N Se Kecamatan Rao.

Tabel 5. Distribusi frekuensi Pengaruh Pembelajaran Pendidikan Jasmani, Olahraga dan kesehatan terhadap Pembinaan Karakter Siswa SMP N 1 Rao

\begin{tabular}{|c|c|c|c|c|}
\hline \multirow[b]{2}{*}{ No } & \multicolumn{4}{|c|}{ Distribusi Frekuensi Smp N 1 Rao } \\
\hline & $\begin{array}{c}\text { Kelas } \\
\text { Interval }\end{array}$ & $\begin{array}{c}\text { Absolut } \\
\text { (Fi) }\end{array}$ & $\begin{array}{c}\text { Relatif } \\
(\%)\end{array}$ & Kategori \\
\hline 1 & $90 \%-100 \%$ & 0,0 & $0,0 \%$ & $\begin{array}{l}\text { Sangat } \\
\text { Baik }\end{array}$ \\
\hline 2 & $80 \%-89 \%$ & 2,0 & $5,0 \%$ & Baik \\
\hline 3 & $65 \%-79 \%$ & 25,0 & $68,0 \%$ & Cukup \\
\hline 4 & $55 \%-64 \%$ & 10,0 & $27,0 \%$ & Kurang \\
\hline 5 & $0 \%-54 \%$ & 0,0 & $0,0 \%$ & $\begin{array}{l}\text { Sangat } \\
\text { Kurang }\end{array}$ \\
\hline & Jumlah & 37 & $100 \%$ & \\
\hline
\end{tabular}


Berdasarkan data distribusi ferkuensi diatas, petsentasi dari 37orang responden ternyata sebanayak 2 orang responden $(5,0 \%)$ termasuk kategori baik, sebanyak 25 orang responnden $(68,0 \%)$ termasuk dalam kategori cukup, sebanyak 10 orang responden $(27,0 \%)$ termasuk kategori kurang sedangkan kategori sangat baik sekali dan kurang sekali tidak ada. Untuk lebih jelasnya dapat dilihat pada grafik dibawah ini:

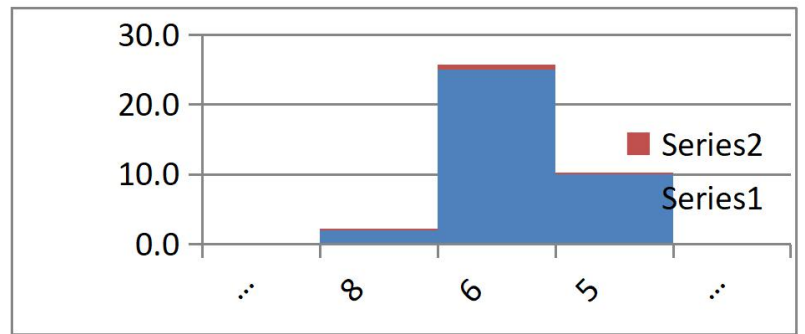

b. Pengaruh Pembelajaran Pendidikan Jasmani, Olahraga dan kesehatan terhadap Pembinaan Karakter Siswa SMP N Se Kecamatan Rao

Tabel 6. Distribusi frekuensi Pengaruh Pembelajaran Pendidikan Jasmani, Olahraga dan kesehatan terhadap Pembinaan Karakter Siswa SMP N 2 Rao

\begin{tabular}{ccccc}
\multicolumn{4}{c}{ Distribusi Frekuensi Smp N 2 Rao } \\
No & $\begin{array}{c}\text { Kelas } \\
\text { Interval }\end{array}$ & $\begin{array}{c}\text { Absolut } \\
\text { (Fi) }\end{array}$ & $\begin{array}{c}\text { Relatif } \\
(\%)\end{array}$ & Kategori \\
\hline 1 & $90 \%-100 \%$ & 0,0 & $0,0 \%$ & Sangat Baik \\
2 & $80 \%-89 \%$ & 0,0 & $0,0 \%$ & Baik \\
3 & $65 \%-79 \%$ & 15,0 & $58,0 \%$ & Cukup \\
4 & $55 \%-64 \%$ & 11,0 & $42,0 \%$ & Kurang \\
& & & & Sangat \\
5 & $0 \%-54 \%$ & 0,0 & $0,0 \%$ & Kurang \\
& Jumlah & 26 & $100 \%$ & \\
\hline
\end{tabular}

Berdasarkan data distribusi ferkuensi diatas, petsentasi dari 26orang responden ternyata sebanayak, sebanyak 15 orang responnden $(58,0 \%)$ termasuk dalam kategori cukup, sebanyak 11 orang responden $(42,0 \%)$ termasuk kategori kurang sedangkan kategori sangat baik,baik, dan sangat kurang sekali tidak ada. Untuk lebih jelasnya dapat dilihat pada grafik dibawah ini:

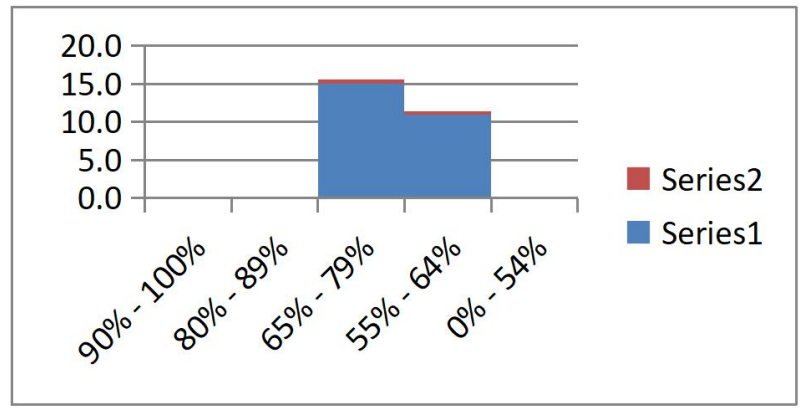

c. Pengaruh Pembelajaran Pendidikan Jasmani, Olahraga dan kesehatan terhadap Pembinaan Karakter Siswa SMP N Se Kecamatan Rao. 
Tabel 7. Distribusi frekuensi Pengaruh Pembelajaran Pendidikan Jasmani, Olahraga dan kesehatan terhadap Pembinaan Karakter Siswa SMP N 3 Rao

\begin{tabular}{ccccc}
\hline \multicolumn{5}{c}{ Distribusi Frekuensi Smp N 3 Rao } \\
N & Relati \\
o & Kelas & $\begin{array}{c}\text { Absolut } \\
\text { f }\end{array}$ & Kategori \\
& Interval & (Fi) & (\%) & \\
\hline & $90 \%-$ & & & \\
1 & $100 \%$ & 0,0 & $0,0 \%$ & Sangat Baik \\
2 & $80 \%-89 \%$ & 1,0 & $8,0 \%$ & Baik \\
3 & $65 \%-79 \%$ & 6,0 & $50,0 \%$ & Cukup \\
4 & $55 \%-64 \%$ & 5,0 & $42,0 \%$ & Kurang \\
& & & & Sangat \\
5 & $0 \%-54 \%$ & 0,0 & $0,0 \%$ & Kurang \\
& Jumlah & 12 & $100 \%$ & \\
\hline
\end{tabular}

Berdasarkan data distribusi ferkuensi diatas, petsentasi dari 12orang responden ternyata sebanayak, sebanyak 1 orang responnden $(8,0 \%)$ termasuk dalam kategori baik, sebanyak 6 orang responden $(50,0 \%)$ termasuk kategori cukup sebanyak 5 orang responden $(42,0 \%)$ termasuk kategori kurang sedangkan kategori sangat baik, dan sangat kurang sekali tidak ada. Untuk lebih jelasnya dapat dilihat pada grafik dibawah ini:

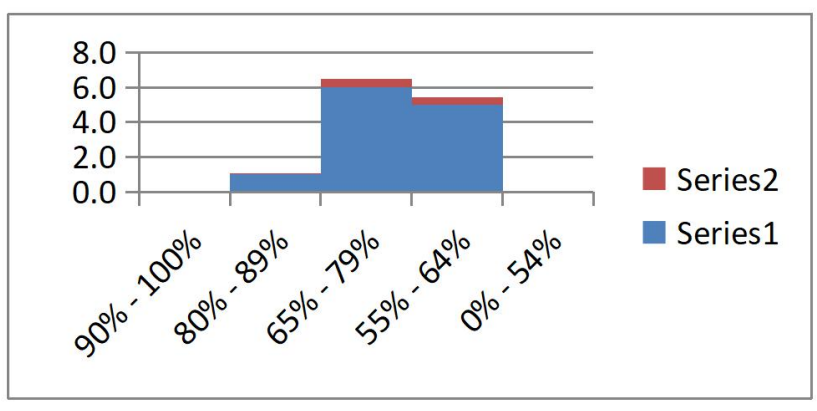

d. Pengaruh Pembelajaran Pendidikan Jasmani, Olahraga dan kesehatan terhadap Pembinaan Karakter Siswa SMP N Se Kecamatan Rao

Tabel 8. Distribusi frekuensi Pengaruh Pembelajaran Pendidikan Jasmani, Olahraga dan kesehatan terhadap Pembinaan Karakter Siswa SMP N Se Kecamatan Rao

\begin{tabular}{ccccc}
\hline \multicolumn{4}{c}{ Distribusi Frekuensi Karakter } \\
No & $\begin{array}{c}\text { Kelas } \\
\text { Interval }\end{array}$ & $\begin{array}{c}\text { Absolut } \\
\text { (Fi) }\end{array}$ & $\begin{array}{c}\text { Relatif } \\
(\%)\end{array}$ & Kategori \\
\hline 1 & $90 \%-100 \%$ & 0 & $0 \%$ & Sangat Baik \\
2 & $80 \%-89 \%$ & 3 & $4 \%$ & Baik \\
3 & $65 \%-79 \%$ & 50 & $67 \%$ & Cukup \\
4 & $55 \%-64 \%$ & 22 & $29 \%$ & Kurang \\
& & & & Sangat \\
5 & $0 \%-54 \%$ & 0 & $0 \%$ & Kurang \\
& Jumlah & 75 & $100 \%$ & \\
\hline
\end{tabular}


Berdasarkan data distribusi ferkuensi diatas, petsentasi dari 75orang responden ternyata sebanayak, sebanyak 3 orang responnden (4\%) termasuk dalam kategori baik, sebanyak 50 orang responden $(67 \%)$ termasuk kategori cukup sebanyak 22 orang responden $(29,0 \%)$ termasuk kategori kurang sedangkan kategori sangat baik, dan sangat kurang sekali tidak ada. Untuk lebih jelasnya dapat dilihat pada grafik dibawah ini:

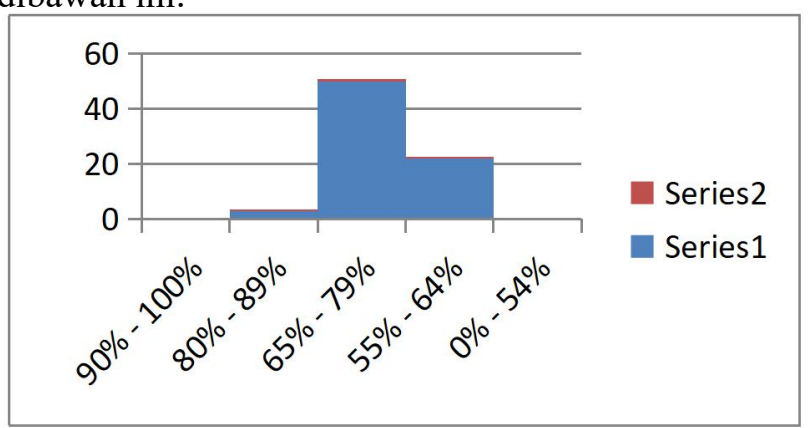

Dari tabel 9 dapat diketahui bahwa indikator tanggung jawab berada pada kategori cukup dengan tingkat pencapaian $74,2 \%$, indikator disiplin berada pada kategori cukup dengan tingkat pencapaian $77 \%$ dan indikator semangat berada pada kategori cukup dengan tingkat pencapaian $73,6 \%$. Jadi dapat disimpulkan rata-rata motivasi kerja keseluruhan berada pada kategori cukup dengan tingkat pencapaian $75 \%$.

\section{A. Analisis Data}

\section{Pengujian Persyaratan Analisis}

Hipotesis penelitian ini diuji dengan menggunakan analisis $t$ test. Sebelum dilakukan analisis $t$ test, terlebih dahulu dilakukan uji normalitas untuk mengetahui apakah data berasal dari populasi yang berdistribusi normal atau tidak. Uji normalitas distribusi variabel Karakter Siswa SMP N Se Kecematan Rao , data analisis dengan statistik uji Liliefors, dengan taraf signifikan yang digunakan sebagai dasar menolak ataupun menerima keputusan normal atau tidaknya suatu distribusi data adalah $\alpha=0,05$.

\section{Tabel 9. Uji normalitas Pembinaan Karakter SMP N Se Kecamatan Rao

Data N Lo Lt Ket

\section{$\begin{array}{lllll}\text { SMP N Se } & 75 & 0.0938 & 0.1023 & \text { Normal }\end{array}$ \\ Kecamatan \\ Rao}

Berdasarkan tabel diatas, untuk data penelitian siswa SMP N Se Kecamatan Rao Lo $=0.0938$ dengan Lt pada $\alpha=0.05=0.1023$ dengan demikian $\mathrm{Lo}<$ dari Lt maka dapat disimpulkan data yang diperoleh berdistribusi normal.

\section{Pengujian Hipotesis}

Pengolahan data dilakukan dengan menghitung Pengaruh Pembelajaran Pendidikan Jasmani, Olahraga dan kesehatan terhadap Pembinaan Karakter Siswa SMP N Se Kecamatan Rao. Hipotesis yang diajukan adalah :

Ho : Tidak dapat pengaruh Pembelajaran Pendidikan Jasmani, Olahraga dan kesehatan terhadap Pembinaan Karakter Siswa SMP N Se Kecamatan Rao.

Ha : Terdapat pengaruh Pembelajaran Pendidikan Jasmani, Olahraga dan kesehatan terhadap Pembinaan Karakter Siswa SMP N Se Kecamatan Rao.

Uji statistik yang digunakan adalah uji t yaitu melihat pengaruh rerata hitung dalam satu kelompok yang sama pada taraf signifikansi 0,05. Dimana hasil analisis menunjukkan bahwa: 
Tabel 10. Rangkuman Hasil Pengujian Hipotesis

\begin{tabular}{ccccc} 
Data & $\mathbf{N}$ & $\mathbf{t}_{\text {hitung }}$ & $\mathbf{t}_{\text {tabel }}$ & Ket \\
\hline $\begin{array}{c}\text { Pembinaan } \\
\text { Karakter }\end{array}$ & 75 & $-6,1894$ & $\begin{array}{c}1,68 \\
53\end{array}$ & $\begin{array}{c}\text { Ho : Ditolak } \\
\text { Ha : Diterima }\end{array}$
\end{tabular}

Berdasarkan hasil analisis pada tabel di atas dapat diketahui bahwa Ho di tolak dan Ha diterima. Hal ini dapat diketahui dimana $t_{\text {hit }}=-6,1894>t_{t a b}=1,6853$ Sehingga disimpulkan bahwa Pembelajaran Pendidikan Jasmani, Olahraga dan kesehatan memberikan pengaruh yang signifikan terhadap Pembinaan Karakter Siswa SMP N Se Kecamatan Rao.

\section{Pembahasan}

Pengaruh Pembelajaran Pendidikan Jasmani, Olahraga dan kesehatanterhadap Pembinaan Karakter Siswa SMP N Se Kecamatan Rao.

Berdasarkan hasil analisis uji hipotesis diperoleh harga $t_{\text {hit }}(-6,1894)>t_{\text {tabel }}(1,6853)$ pada taraf signifikansi $\alpha=0,05$ pada jumlah sampel berjumlah 75. Jadi, dapat disimpulkan bahwa Ho ditolak dan Ha diterima. Dengan demikian Pembelajaran Pendidikan Jasmani, Olahraga dan kesehatan memberikan pengaruh yang signifikan terhadap Pembinaan Karakter Siswa SMP N Se Kecamatan Rao.

Ratna Megawangi (2006;67), menuliskan bahwa tujuan pendidikan adalah generasi muda dapat, menghayati, memahami, mengamalkan nilai-nilai karakter dalam kehidupan. Pendidikan karakter merupakan proses transformasi nilai-nilai mmoralitas manusia yang didasari dan dilakukan dalam tindakan nyata. Disini ada satu proses Pembinaan nilai dan sikap yang didasari mengapa nilai itu dilakukan.

Masih dalam kaitannya dengan Pembinaan karakter, Thomas Lickona (2013:72), berpendapat "karakter terbentuk dari tiga macam bagian yang saling berkaitan: pengetahuan moral, perasan moral, dan perilaku moral". Karakter yang baik terdiri atas mengetahui kebaikan, menginginkan kebaikan, dan melakukan kebaikan. Untuk merealisasikan hal ini diperlukan pembiasaan dalam pemikiran, pembiasaan dalam hati, dan pembiasaan dalam perbuatan. Tiga hal ini merupakan suatu bagian yang tidak dapat terpisahkan. Seseorang yang memiliki karakter baik tentulah sebelumnya ia memiliki pengetahuan yang mendalam tentang kebaikan itu. Kemudian ia merasakan kerugian dan kesedihan yang mendalam jika tidak melaukaknnya, dan muncul keinginan yang kuat untuk merealisasikannya. Jika perasaan moral seperti itu sudah semakin menguat, maka sesudah itu ia akan melakukan kebaikan yang diinginkannya. Demikianlah gambaran proses Pembinaan karakter menurut Thomas Lickona.

Prayitno (2010:6), memberikan agumentasi pentingnya pendidikan karakter sebagai berikut: Pertama, bahwa pedidikan tidak boleh gagal. Pendidikan harus berhasil mengantarkan peserta didik menjadi pribadi-pribadi berkarakter dan cerdas sebagai jaminan bagi terwujudnya kehidupan (dalam segenap tatarannya, yaitu tataran individual, keluarga, kelompok, dan masyarakat, bangsa dan negara) yang berhasil mensejahterakan dan membahagiakan. Berdasarkan penjelasan diatas, dapat dikatakan bahwa pada hakikatnya pendidikan adalah Pembinaan karakter. Kedua, kenyataan bahwa asyarakat kita sudah disesaki dan diceedear oleh suasana kekisruhan dan ketidaknyamanan. Kedamaian, kesejahteraan, kebahagiaan dan harapan-harapan yang menyejukkan tampaknya semakin tergerus oleh perilaku dan praktek berbagai penyimpangan. Untuk itu perlu diciptakan satu suasana yang lebih kondusif bagi kehidupan yang bisa memunculkan harapan. Sarana yang bisa dilakukan untuk merealisasikan kondisi itu adalah pendidikan. Ketiga, adanya satu keinginan yang besar agar terealisasi suatu pola pedidiakan yang bisa menumbuhkan perilaku sopan santun, tat krama, jujur, dan bertanggung jawab, disiplin dan bekerja keras. Pendidikan disekolah diharapkan juga berorientasi 
pada kecerdasan peserta didiknya seperti sikap kritis-objektif-analitis, kreativ dan inovativ, mampu membuat rencana dan merencanakan solusi dan sebagainya.

Akhirnya didasarkan pada pembuktikan uji statistik, disimpulkan bahwa Pembelajaran Pendidikan Jasmani, Olahraga dan kesehatan memberikan pengaruh terhadap Pembinaan Karakter.

\section{KESIMPULAN}

Berdasarkan analisis data dan pembahasaan, maka dapat disimpulkan bahwa: Pembelajaran Pendidikan Jasmani, Olahraga dan kesehatan memberikan pengaruh yang berarti terhadap Pembinaan Karakter Siswa SMP Se Kecamatan Rao. Peneliti memberikan saran yaitu: 1) Orang tua, Guru, lebih memperhatikan perkembanganya anak-anaknya. 2) Peneliti yang akan meneliti mengenai Pembelajaran Pendidikan Jasmani, Olahraga dan Kesehatan Terhadap Pembinaan Karakter Siswa agar dapat dilakukan dengan lebih lengkap dan sempurna lagi. 3) Gunakan teknis analisis data yang lain sebagai perbandingan mana yang menunjukan hasil yang mendekati kesempurnaan aatau agar dapat memberikan hasil yang sama dengan teknik analisi data yang penulis gunakan.

Peneliti yang akan meneliti mengenai Pembelajaran Pendidikan Jasmani, Olahraga dan Kesehatan Terhadap Pembinaan Karakter Siswa agar dapat menggugunakan jenis instrumen dengan anket terbuka dengan skala Lickert.

\section{DAFTAR RUJUKAN}

Apriagus. 2012. Olahraga Kebugaran Jasmani sebagai Suatu Pengantar. Padang: Sukabina Press

Gusril. (2008). Buku Ajar Metodologi Penelitian. Padang: FIK UNP.

Badan Penelitian dan Pengembagan Pusat Kurikulum. 2010. Pengembagan

Pendidikan Budaya dan Karakter Bangsa. Jakarta; Kementrian Pendidikan

Nasional.

Danim, Sudarwan dan Khairir. 2010. Psikologi Pendidikan. Bandung; Alfabeta

Kurikulum Tingakat Satuan Pendidikan. 2010. Panduan Pengembangan Silabus

Pembelajaran. Jakarta; Kementrian Pendidikan Nasional.

Megawangi, Ratna. 2004. Pendidikan Karakter. Jakarta.

Muslich, Masnur. 2011. Pendidikan Karakter. Jakrta; PT Bumi Aksara

Peraturan Menteri Pendidikan Nasional Republik Indonesia No 22 Tahun 2006

Standar Isi untuk Satuan Dasar dan Menengah.

Sudjana. (2001). Metode Statistik. Bandung: Tarsito..

Sugiyono (2012). Metode Penelitian. PT. Sukabina.

Suharsimi, Arikunto (2011). Prosedur Penelitian. Bandung.

Thontowi, A. 2012. Hakekat Religiusitas. (Online),

http://www.sumsel.kemenag.go.id), diakses 4 September 2012.

Yusuf. (2007). Metodelogi Penelitian. Padang: FIK UNP

Departemen Pendidikan dan Kebudayaan, Kamus Besar Bahasa Indonesia,

(Jakarta: Balai Pustaka, 1990), hlm. 367. 